\title{
FORMULASI GRANUL ANTIOKSIDAN EKSTRAK ETANOL DAUN SIRSAK (Anonna muricata Linn.) MENGGUNAKAN METODE GRANULASI BASAH
}

\author{
Raehan Natul Jannah*, Jaka Fadraersada, Lisna Meylina, Adam M. Ramadhan
}

Laboratorium Penelitian dan Pengembangan Kefarmasian "Farmaka Tropis", Fakultas Farmasi, Universitas Mulawarman, Samarinda, Indonesia

*Email: raehan17@gmail.com

\begin{abstract}
Soursop Leaves (Anonna muricata Linn.) is a medicinal plant that has various benefits. One of the benefits of soursop leaves is as an antioxidant. The purpose of this study is to determine the antioxidant activity and evaluation of the granular preparations of its extract. Antioxidant activity obtained by DPPH method and granule formulation obtained by wet granulation method. The antioxidant activity result is $19.24 \mathrm{ppm}$, which is a very strong antioxidant's activity. Granule preparation evaluation results are $3.22 \%$ for moisture test, $14.01 \mathrm{~g} / \mathrm{s}$ for flow rate test, $25.31^{\circ}$ for angle of repose test, $5.77 \%$ for compressibility which fulfills the requirements of proper granule preparation criteria and the particle size distribution is most dominant in the range 426-850 $\mu \mathrm{m}$ which incudes the category of coarse powder.
\end{abstract}

Keywords: Antioxidant, DPPH method, soursop leaves, wet granulation

\begin{abstract}
ABSTRAK
Daun Sirsak (Anonna muricata Linn.) merupakan tanaman obat yang memiliki berbagai macam manfaat. Salah satu manfaat daun sirsak yaitu sebagai antioksidan. Tujuan dari penelitian ini, untuk menentukan aktivitas antioksidan dan evaluasi sediaan granul dari ekstrak etanol daun sirsak. Pengujian aktivitas antioksidan dilakukan dengan metode DPPH dan formulasi granul dilakukan dengan metode granuasi basah. Hasil yang diperoleh aktivitas antioksidan ekstrak etanol daun sirsak yaitu 19,24 ppm yang termasuk kategori antioksidan sangat kuat dan hasil evaluasi sediaan granul yaitu uji kelembaban $3,22 \%$, laju alir $14,01 \mathrm{~g} / \mathrm{s}$, sudut istirahat $25,31^{\circ}$, kompresibilitas $5,77 \%$ yang memenuhi persyarataan kriteria sediaan granul yang baik serta distribusi ukuran partikel paling dominan pada rentang 426-850 $\mu \mathrm{m}$ yang termasuk kategori serbuk kasar.
\end{abstract}

Kata Kunci: Antioksidan, daun sirsak, granulasi basah, metode DPPH

DOI: https://doi.org/10.25026/mpc.v8i1.310 


\section{PENDAHULUAN}

Tanaman sirsak secara luas digunakan untuk pengobatan seperti hipertensi, diabetes, demam, diare, infeksi bakteri, disentri, inflamasi, dan kanker $^{[1]}$. Bagian yang biasanya dimanfaatkan sebagai obat yaitu daun yang diketahui mengandung beberapa senyawa golongan flavonoid seperti gentistic acid, annomuricin, anomurine dan lain-lain ${ }^{[2]}$. Senyawa golongan flavonoid merupakan senyawa yang berpotensi sebagai antioksidan ${ }^{[3]}$. Antioksidan merupakan senyawa yang dapat menangkal reaktivitas radikal bebas dan molekul yang sangat reaktif dalam tubuh manusia, sehingga kerusakan sel dapat dihambat ${ }^{[4]}$.

Berdasarkan

penelitian sebelumnya yang dilakukan oleh Laili Rahmawati, daun sirsak diketahui memiliki kadar air 7,23\%, senyawa larut air 49,82\%, dan senyawa larut etanol $64,04 \%{ }^{[5]}$. Selain itu, aktivitas antioksidan ekstrak etanol daun sirsak termasuk kategori antioksidan sangat kuat dengan $\mathrm{IC}_{50}$ sebesar $40,61 \mathrm{ppm}^{[6]}$. Konsentrasi ekstrak etanol daun sirsak yang diperoleh akan diformulasikan ke dalam sediaan granul. Granul merupakan produk yang dihasilkan dari proses granulasi baik itu granulasi basah maupun granulasi kering. Granul bukan hanya sebagai produk antara untuk dijadikan sediaan tablet. Tetapi granul juga merupakan sediaan obat tersendiri dengan tujuan agar lebih baik penggunaannya dan takarannya lebih pasti $^{[7]}$, sehingga melatarbelakangi dilakukannya penelitian ini untuk menentukan aktivitas antioksidan ekstrak etanol daun sirsak dan memformulasikan daun sirsak menjadi sediaan granul.

\section{METODE PENELITIAN}

\section{Alat dan Bahan}

Alat yang digunakan dalam penelitian ini yaitu gelas kimia (Iwaki CTE33), mortir, stamper, mesh ayakan
(MBT ASTM standard test sieve) 20; 40; 60; 80; dan 100, mechanical tapping device, powder flow tester, timbangan analitik (Precisa), moisture analyzer (Shimadzu), rak tabung, loyang, spatel, oven (Froilabo), wadah maserasi, sendok tanduk, kipas angin, cawan, kuvet, corong buchner, spektrofotometer $U V$ Visible (Dynamica), rotary evaporator (Buchi Switzerland), labu ukur (Pyrex), shaker (MBT) dan alat kaca yang sering digunakan.

Bahan yang digunakan dalam penelitian ini yaitu daun sirsak, etanol p.a (Emsure), etanol 96\%, kertas saring, plastic wrap (Cling wrap), polivinilpirolidone K-30, laktosa, starch $1500 \mathrm{G}$, silika gel, dan 1,1-Diphenyl-2Picrylhydrazil (DPPH) (Sigma Aldrich).

\section{Ekstraksi}

Sampel daun sirsak (Annona muricata Linn.) diperoleh dari Kelurahan Handil Bakti, Kecamatan Palaran, Kota Samarinda, Provinsi Kalimantan Timur, Indonesia. Daun sirsak diambil sebanyak $2 \mathrm{~kg}$ disortasi basah, dicuci dan dikeringkan di oven. Kemudian dirajang sehingga diperoleh simplisia daun sirsak yang siap diekstraksi. Simplisia sebanyak $100 \mathrm{~g}$ dimaserasi menggunakan etanol 96 $\%$. Sampel disaring dan filtrat di uapkan menggunakan rotary evaporator pada suhu $50^{\circ} \mathrm{C}$ hingga diperoleh ekstrak kental $28 \mathrm{~g}$.

\section{Aktivitas Antioksidan}

Pengujian aktivitas antioksidan dilakukan dengan metode DPPH. Konsentrasi DPPH yang digunakan dalam penelitian ini yaitu $40 \mathrm{ppm}$ pada panjang gelombang $518 \mathrm{~nm}$. Penentuan seri konsentrasi dilakukan dengan cara membuat larutan stok 1000 ppm lalu dibuat seri konsentrasi 10 ppm, 20 ppm, 30 ppm, 40 ppm, dan 50 ppm. Kemudian diukur absorbansinya pada panjang gelombang maksimum $518 \mathrm{~nm}$. Dilakukan replikasi sebanyak 3 kali dan ditentukan nilai $\mathrm{IC}_{50}$. 


\section{Granulasi}

Formulasi sediaan granul antioksidan ekstrak etanol daun sirsak dilakukan dengan metode granulasi basah. Formula yang digunakan dalam penelitian ini dapat dilihat pada Tabel 1 . Formulasi granul dilakukan dengan mencampurkan laktosa dan starch 1500 $G$ sampai homogen. Setelah itu, ekstrak dilarutkan dengan etanol 96\%, dimasukkan ke dalam mortir yang berisi PVP K-30 digerus hingga terbentuk mucilago, kemudian dimasukkan ke dalam campuran laktosa dan starch 1500 $G$. Dibuat granulasi dengan menggunakan ayakan mesh 20. Dikeringkan dalam oven pada suhu 35$45^{\circ} \mathrm{C}$ selama 3 menit, lalu diayak kembali menggunakan ayakan mesh 20 .

\section{Evaluasi Granul}

\section{Kelembaban}

Pengujian kelembaban dilakukan dengan cara menggunakan alat moisture analyzer. Terlebih dahulu ditimbang 0,5 g granul lalu dimasukkan ke dalam alat moisture analyzer. Kemudian ditunggu sampai lampu mati yang menunjukkan proses telah selesai.

\section{Laju alir}

Pengujian waktu alir dilakukan dengan cara dimasukkan $10 \mathrm{~g}$ granul ke dalam corong. Dibuka penutup bawah corong. Dihitung waktu jatuhnya granul menggunakan stopwatch.

\section{Sudut istirahat}

Pengujian sudut istirahat dilakukan dengan cara dimasukkan $10 \mathrm{~g}$ granul ke dalam corong. Dibuka penutup bawah corong. Diukur diameter dan tinggi granul.

\section{Densitas dan Kompresibilitas}

Pengujian densitas dan kompresibilitas dilakukan dengan cara ditimbang gelas ukur 25 mL. Dimasukkan granul ke dalam gelas ukur hingga volume $25 \mathrm{~mL}$. Dicatat berat gelas ukur $25 \mathrm{~mL}$ yang berisi granul. Dicatat volume awal granul. Dinyalakan instrument sampai terjadi hentakan. Dicatat volume akhir dan dihitung nilai kompresibilitas.

\section{Distribusi ukuran partikel}

Pengujian distribusi ukuran partikel dilakukan dengan cara ditimbang 5 g granul. Dirangkai ayakan dari mesh yang paling besar hingga paling kecil. Dimasukkan granul ke dalam ayakan paling atas. Dinyalakan alat selama 5 menit. Ditimbang granul yang tersisa pada ayakan.

\section{HASIL DAN PEMBAHASAN}

\section{Aktivitas Antioksidan Ekstrak Etanol Daun Sirsak}

Hasil uji aktivitas antioksidan dengan metode DPPH dinyatakan dengan nilai $\mathrm{IC}_{50}$. Berdasarkan pengujian yang telah dilakukan maka didapatkan nilai IC $_{50}$ ekstrak etanol daun sirsak adalah 19,24 ppm yang termasuk kategori antioksidan sangat kuat yang dapat dilihat pada Tabel 2. Konsentrasi dengan \% aktivitas antioksidan berbanding lurus, tetapi berbanding terbalik dengan absorbansinya. Hal tersebut dikarenakan semakin tinggi konsentrasi ekstrak, maka semakin tinggi pula kandungan zat antioksidannya, sehingga semakin banyak partikel DPPH yang akan dihambat oleh ekstrak, sehingga nilai absorbansi semakin kecil ${ }^{[8]}$. Semakin kecil nilai $\mathrm{IC}_{50}$ maka semakin kuat aktivitas antioksidannya Tingkatan Aktivitas Antioksidan pada metode DPPH terdiri dari 4 yaitu $\mathrm{IC}_{50}<50 \mathrm{ppm}$ sangat kuat, $\mathrm{IC}_{50}$ 50-100 ppm kuat, IC 50 100-250 ppm sedang, dan $\mathrm{IC}_{50} 250-500$ ppm lemah ${ }^{[9]}$. 
Tabel 1. Formula Granul Ekstrak Etanol Daun Sirsak

\begin{tabular}{lcc}
\hline Nama Bahan & Formula A & Formula B \\
\hline Ekstrak etanol daun sirsak & - & $1,03 \%$ \\
Starch $1500 G$ & $5,10 \%$ & $5,10 \%$ \\
PVP K-30 & $5,10 \%$ & $5,10 \%$ \\
Laktosa & $89,80 \%$ & $88,77 \%$ \\
\hline
\end{tabular}

Keterangan :

Formula A : Formula basis granul ekstrak etanol daun sirsak.

Formula B : Formula granul ekstrak etanol daun sirsak.

Tabel 2. Pengujian Aktivitas Antioksidan Ekstrak Etanol Daun Sirsak

\begin{tabular}{cccc}
\hline Konsentrasi $(\mathrm{ppm})$ & Absorbansi & Aktivitas Antioksidan $(\%)$ & $\mathrm{IC}_{50}(\mathrm{ppm})$ \\
\hline Blanko & 0,622 & 0 & \\
10 & 0,347 & 44,21 & \\
20 & 0,314 & 49,51 & 19,24 \\
30 & 0,280 & 54,98 & \\
40 & 0,179 & 71,22 & \\
50 & 0,143 & 77,00 & \\
\hline
\end{tabular}

Keterangan :

Blanko : Etanol p.a dan DPPH

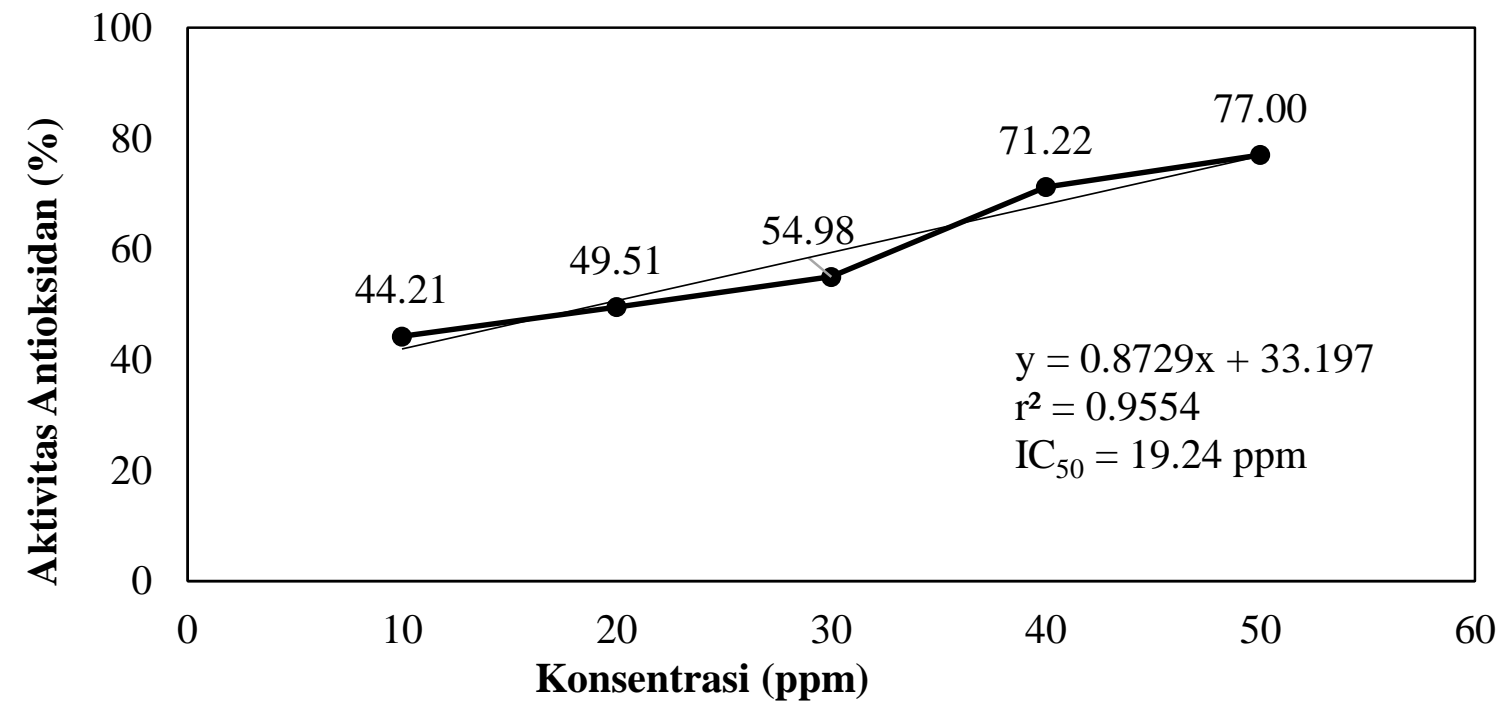

Gambar 1. Aktivitas Antioksidan Ekstrak Etanol Daun Sirsak

Tabel 3. Uji Sifat Fisik Granul Optimasi dan Granul Ekstrak Etanol Daun Sirsak

\begin{tabular}{lcc}
\hline Parameter & Formula A & Formula B \\
\hline Kelembaban (\%) & 3,07 & 3,22 \\
Laju Alir (g/s) & 10,03 & 14,01 \\
Sudut Istirahat $\left({ }^{\circ}\right)$ & 24,28 & 25,31 \\
Kompresibilitas $(\%)$ & 13,91 & 5,77 \\
\hline
\end{tabular}




\section{Karakteristik Sifat Fisik Granul Ekstrak Etanol Daun}

Karakteristik sifat fisik granul ekstrak etanol daun sirsak dapat dilihat pada Tabel 3. Berdasarkan uji kelembaban yang dilakukan, formula A dan B memiliki kelembaban yang baik yaitu 3,07\% dan 3,22\% yang memenuhi persyaratan kelembaban granul yang baik yaitu 2-4 \% [10]. Laju alir suatu bahan dikatakan dapat bebas mengalir jika kecepatan alirnya $>10 \mathrm{~g} / \operatorname{detik}^{[11]}$ atau waktu alirnya $\leq 1$ detik untuk $10 \mathrm{~g}$ granul [12]. Berdasarkan uji laju alir yang dilakukan pada formula $B$ granul memiliki laju alir yang lebih baik dibandingkan formula A. Hal tersebut dikarenakan pada formula B terdapat ekstrak etanol daun sirsak yang mengandung minyak sehingga, meningkatkan laju alir suatu granul. Selain itu, dapat juga dikarenakan bentuk granul yang relatif besar sehingga meningkatkan laju alir pada granul. Partikel yang memiliki ukuran relatif besar, memiliki gaya kohesi yang kecil sehingga laju alir akan semakin mudah $^{[13]}$.

Sudut istirahat ialah sudut yang terbentuk antara permukaan gundukan granul dengan bidang horizontal. Sudut istirahat dikatakan baik atau dapat mengalir bebas jika memiliki sudut istirahat lebih kecil atau sama dengan $30^{\circ}$ jika sudut istirahatnya lebih besar atau sama dengan $40^{\circ}$ biasanya daya mengalirnya kurang baik ${ }^{[10]}$. Adapun kategori sifat aliran dan keterkaitan dengan sudut istirahat yaitu, sifat aliran bagus sekali $\left(25-30^{\circ}\right)$, baik $\left(31-35^{\circ}\right)$, cukup $\left(36-40^{\circ}\right)$, lewat $\left(41-45^{\circ}\right)$, buruk $\left(46-55^{\circ}\right)$, sangat buruk $\left(56-65^{\circ}\right)$, dan sangat-sangat buruk $\left(>66^{\circ}\right)$ [14]. Berdasarkan uji sudut diam yang telah dilakukan formula A dan B memiliki sudut istirahat yang bagus sekali yang menunjukkan bahwa granul dapat mengalir bebas. Sudut istirahat berbanding terbalik dengan laju alir, semakin besar laju alir maka sudut istirahatnya akan semakin kecil, sehingga menghasilkan granul yang dapat mengalir bebas ke corong hopper. Corong hopper merupakan salah satu bagian dari alat cetak tablet yang berfungsi mengalirkan granul ke mesin cetak tablet ${ }^{[10]}$.

\section{Bulk dan tapped density} merupakan suatu pengujian granul dengan tujuan untuk pengukuran nilai densitas yaitu untuk menghitung nilai kompresibilitas dari granul yang dibuat. Tapped density merupakan massa granul per satuan volume setelah diberi ketukan mekanik, sedangkan bulk density merupakan massa granul per satuan volume sebelum diberi ketukan mekanik. Kompresibilitas merupakan suatu kemampuan pembentukan massa yang utuh dan juga stabil ketika diberikan tekanan. Tujuan dari uji kompresibilitas yaitu selain untuk melihat kemampuan granul untuk tetap kompak dengan adanya kompresi, kompresibilitas juga dapat digunakan untuk melihat karakteristik aliran granul. Adapun karakteristik aliran granul yaitu, free flowing (5-12\%), good (12-16\%), fair (18-21\%), poor (23-35\%), very poor (33$38 \%)$, dan extremely poor $(>40 \%)^{[15]}$. Berdasarkan penelitian yang telah dilakukan didapatkan nilai kompresibilitas pada formula A 13,91\% yang termasuk kategori baik dan formula B 5,77\% yang termasuk kategori sangat mudah mengalir. Semakin rendah kompresibilitas granul, semakin tinggi kerapatan granul setelah mengalami kompresi sehingga semakin kompak massa granul tersebut ${ }^{[16]}$.

Distribusi ukuran partikel dilakukan dengan menggunakan metode pengayakan. Metode ini berfungsi untuk mengukur distribusi ukuran partikel dengan cara menggunakan 5 mesh ayakan yang disusun secara berturut, dimana mesh ayakan yang paling kasar diletakkan pada bagian paling atas ${ }^{[17]}$. Berdasarkan hasil penelitian yang telah 
dilakukan, pada Gambar 2 menggambarkan distribusi ukuran granul pada formula A dan formula B. Granul memiliki distribusi ukuran partikel dengan rentang ukuran partikel paling dominan pada 426-850 $\mu \mathrm{m}$ atau dengan ukuran mesh 20 yang termasuk ukuran partikel serbuk kasar ${ }^{[13]}$. Hal ini terjadi kemungkinan karena proses granulasi dilakukan dengan menggunakan ayakan mesh 20 sehingga granul yang terbentuk dominan berada pada ukuran 426-850 $\mu \mathrm{m}$.

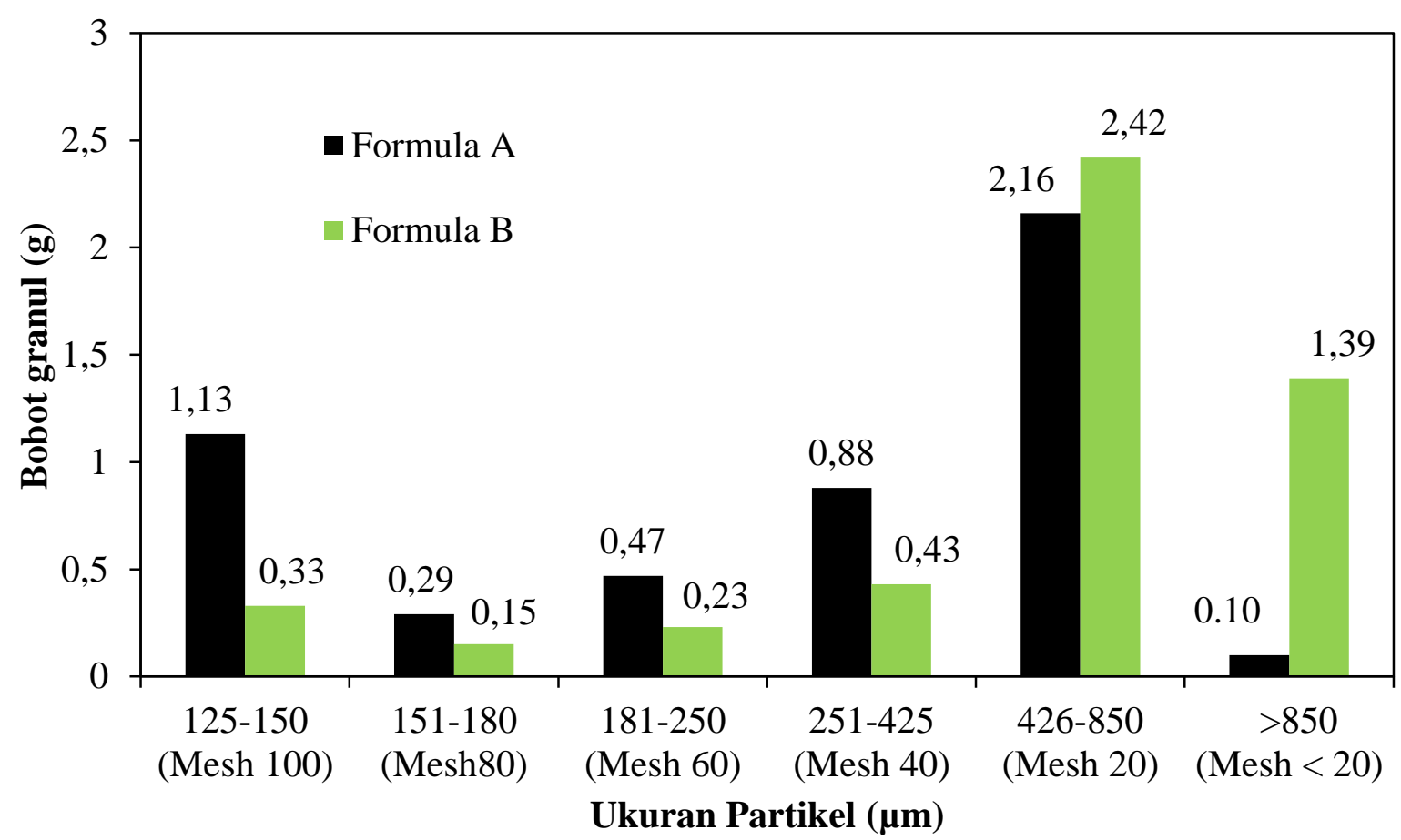

Gambar 2. Distribusi Ukuran Partikel

Keterangan :

Formula A : Formula basis granul ekstrak etanol daun sirsak

Formula B : Formula granul ekstrak etanol daun sirsak

\section{KESIMPULAN}

Berdasarkan penelitian yang telah dilakukan, diperoleh aktivitas antioksidan ekstrak etanol daun sirsak (Annona muricata Linn.) dengan nilai $\mathrm{IC}_{50} 19,24$ ppm yang termasuk kategori sangat kuat dan hasil evaluasi granul dengan parameter uji kelembaban 3,22\%, laju alir $14,01 \mathrm{~g} / \mathrm{s}$, sudut istirahat $25,31^{\circ}$, kompresibilitas $5,77 \%$ yang memenuhi persyarataan kriteria sediaan granul yang baik serta distribusi ukuran partikel paling dominan pada rentang $426-850 \mu \mathrm{m}$ yang termasuk kategori serbuk kasar.

\section{DAFTAR PUSTAKA}

[1] Tellez AVC, Efigenia MG, Elhadi MY, Eva NOV. 2016. Annona muricata: A Comprehensive Review On Its Traditional Medicinal Uses, Phytochemicals, Pharmacological Activities, Mechanisms of Action And Toxicity. Arabian Journal of Chemistry. King Saudi University Hal 1-30.

[2] Hidayat, Syamsul dan Rodame M. Napitupulu. 2015. Kitab Tumbuhan Obat. Jakarta: Bukit Permai. 
[3] Kurniasih N, Mimin K, Nurhasanah, Riska PS, Riza W. 2015. Potensi Daun Sirsak (Annona muricata linn), Daun Binahong (Anredera cordifolia (Ten) Steenis), Dan Daun Benalu Mangga (Dendrophthoe pentandra) Sebagai Antioksidan Pencegah Kanker. Jurnal Volume IX No. 1 ISSN 1979-8911.

[4] Winarsi, Hery. 2007. Antioksidan Alami Dan Radikal Bebas Potensi Dan Aplikasinya Dalam Kesehatan. Yogyakarta: Penerbit Kanisius.

[5] Rahmawati, Laili. 2018. Skripsi. Optimasi Zat Pengisi Pada Sediaan Serbuk Ekstrak Daun Sirsak (Annona muricata Linn). Universitas Mulawarman: Samarinda.

[6] Sari, Deasy Novia. 2017. Skripsi. Stabilitas Antioksidan Sediaan Masker Peel Off Berbahan Aktif Ekstrak Daun Sirsak (Annona muricate Linn). Universitas Mulawarman: Samarinda.

[7] Mulyadi, M, Dafit, Ika YA, Binar AD. 2011. Formulasi Granul Instan Jus Kelopak Bunga Rosela (Hibiscus Sabdariffa L) Dengan Variasi Konsentrasi Povidon Sebagai Bahan Pengikat Serta Kontrol Kualitasnya. Pharmacy, Vol.08 No. 03 Desember 2011 ISSN 1693-3591.

[8] Maulidha N, Aditya F, dan Muhammad AM. 2015. Uji Aktivitas Antioksidan Ekstrak Daun Sirih Hitam (Piper sp.) terhadap DPPH (1,1-diphenyl-2-picryl hydrazyl). Jurnal Sains dan Kesehatan. 2015. Vol 1. No 1. 16.

[9] Putri, Ade Aprilia Surya dan Nurul Hidajati. 2015. Uji Aktivitas Antioksidan Senyawa Fenolik Ekstrak Metanol Kulit Batang Tumbuhan Nyiri Batu (Xylocarpus moluccensis). UNSEA Journal of Chemistry Volume 4 No 1.

[10]Lachman, L., Herbert A. Lieberman, Joseph L. Kanig. 1994. Teori Dan Praktek Farmasi Industri. Terjemahan oleh Siti Suyatmi. Jakarta: Universitas Indonesia.

[11]Kailaku SI, Jayeng S dan Hernani. 2012. Formulasi Granul Efervesen Kaya Antioksidan Dari Ekstrak Daun Gambir. J. Pascapanen 9(1) 2012: 27-34.

[12]Rori WM, Paulina VYY, dan Sri S. 2016. Formulasi Dan Evaluasi Sediaan Tablet Ekstrak Daun Gedi Hijau (Abelmoschus manihot) Dengan Metode Granulasi Basah. PHARMACON Jurnal Ilmiah Farmasi-UNSRAT Vol. 5 No. 2.

[13] Sinko, Patrick J. 2011. Martin Farmasi Fisika Dan Ilmu Farmasetika. Jakarta: EGC.

[14]Agoes, Goeswin.2012. Sediaan Farmasi Padat. Bandung: Penerbit ITB.

[15]Gad, Shayne Cox. 2008. Pharmaceutical Manufacturing Handbook Production And Processes. A John Wiley \& Sons Inc Hoboken: New Jersey.

[16] Winarti W, Kartiningsih, Ratna D, Sarah Z, Indhit N. 2016. Formulasi Sediaan Tablet Ekstrak Sambung Nyawa (Gynurae procumbens (Lour).Merr) sebagai Kandidat Antidiabetes. Jurnal Ilmu Kefarmasian Indonesia halaman. 240-245

[17] Niazi, Sarfaraz K. 2004. Handbook Of Pharmaceutical Manufacturing Formulation, Uncompressed Solid Products.Volume 2. CRC Press: Boca Raton London New York Washington, D.C. 